\title{
Non-communicable disease comorbidities in KwaZulu-Natal Province, South Africa
}

\author{
S B Kushitor, ${ }^{1} \mathrm{PhD}$; O A Sanuade, ${ }^{2,3} \mathrm{PhD} ; \mathrm{L}$ Baatiema, ${ }^{2,4} \mathrm{PhD} ; \mathrm{M}$ K Kushitor, ${ }^{5} \mathrm{PhD}$; E K Afrifa-Anane, ${ }^{6} \mathrm{PhD} ; \mathrm{R}$ B Awuah, ${ }^{7,8} \mathrm{PhD}$ \\ ${ }^{1}$ Food Security Initiative and Centre for Complex Systems in Transition, Stellenbosch University, Stellenbosch, South Africa \\ ${ }^{2}$ Noguchi Memorial Institute for Medical Research, University of Ghana, Accra, Ghana \\ ${ }^{3}$ Institute for Global Health, University College London, UK \\ ${ }^{4}$ Department of Health Policy, Planning and Management, School of Public Health, University of Ghana, Accra, Ghana \\ ${ }^{5}$ Department of Health, Policy Planning and Management, School of Public Health, University of Health and Allied Sciences, Hohoe, Ghana \\ ${ }^{6}$ Akrofi-Christaller Institute of Theology, Mission and Culture, Akropong, Ghana \\ ${ }^{7}$ Regional Institute for Population Studies, University of Ghana, Accra, Ghana \\ ${ }^{8}$ Vital Strategies, New York, USA
}

Corresponding author: SB Kushitor(boatemaa@sun.ac.za)

Background. The prevalence of chronic non-communicable disease (NCD) comorbidity in low- to middle-income countries is increasing, yet evidence on the pattern, prevalence, awareness and treatment of NCD comorbidity is inadequate.

Objectives. To investigate the prevalence, awareness, treatment and control of comorbid hypertension and diabetes, and the underlying risk factors in Mpumza, KwaZulu-Natal Province, South Africa (SA).

Methods. Data were gathered by the SA Human Sciences Research Council from 587 participants in KwaZulu-Natal in 2015. Percentages were used to describe all the variables. Cross-tabulations and $\chi^{2}$ tests were used to describe variations in the prevalences of hypertension, diabetes and comorbidities according to sociodemographic and socioeconomic variables and lifestyle risk factors.

Results. Approximately a third of the participants had hypertension (32\%) and $9 \%$ had diabetes. The prevalence of comorbid hypertension and diabetes was $6 \%$, and this was significantly higher among women, the aged, the obese, and the formerly married compared with their counterparts. Comorbidity awareness was high (86\%). Although most of the participants with comorbidities were being treated with lifestyle changes, insulin and antihypertensive medication (74\%), control of comorbidities was low (13\%).

Conclusion. The study reported a higher burden of comorbid hypertension and diabetes among vulnerable populations in Mpumza, SA, particularly women, the obese, and those with a low level of education. In addition, control of comorbidities was low. Developing appropriate interventions to improve control of comorbidities can reduce the risk of macrovascular and microvascular diseases in this population.

S Afr Med J 2021;111(2):149-158. https://doi.org/10.7196/SAMJ.2021.v111i2.14744

Globally, the past few decades have witnessed a major rise in non-communicable diseases (NCDs) due to the growing ageing population, increasingly unhealthy lifestyles, and rapid unplanned urbanisation. ${ }^{[1,2]}$ At the same time, chronic multimorbidity (also referred to as NCD comorbidities), defined in the context of this article as the co-occurrence of two or more NCDs, ${ }^{[3]}$ is also increasing to an unprecedented extent. ${ }^{[4,5]}$ The prevalence of multimorbidity in low- to middle-income countries (LMICs) is increasing rapidly. ${ }^{[6,7]}$ People living with NCD multimorbidity have a high healthcare utilisation rate ${ }^{[8-10]}$ and high rates of hospitalisation. ${ }^{[11,12]} \mathrm{A}$ study in the USA reported that as many as $65 \%$ of hospital medical experiences were associated with NCD multimorbidity. ${ }^{[13]}$ Furthermore, an intersection of NCDs and the Sustainable Development Goals (SDGs) has recently been recognised in policy efforts towards and discourses on the achievement of the SDGs. ${ }^{[1]}$ This is attributed to the fact that the growing burden of NCDs is likely to retard socioeconomic development and growth and overall attainment of the SDGs. Tackling the high burden of NCDs in the course of achieving the SDGs will therefore require transformative change across the health system to tackle the growing burden of NCD multimorbidity. Such transformative change must include initiatives to gather adequate and reliable NCD data, monitor and treat NCDs, and enhance policy coherence by addressing the challenges presented by high levels of comorbidities.

Despite the growing body of research on the multimorbidity burden from NCDs, international literature on multimorbidity is still insufficient, and existing data on multimorbidity reflect situations in high-income countries. ${ }^{[14]} \mathrm{A}$ key limitation of existing information on multimorbidity is that evidence on the pattern, prevalence, awareness and treatment of people with NCD multimorbidity is inadequate. In the context of South Africa (SA), although studies have advanced understanding of the rising burden of NCDs, ${ }^{[15,16]}$ there is a paucity of information on the prevalence, awareness and treatment of multimorbidity. Knowledge of the underlying risk factors for the growing burden of NCD-related multimorbidity in this setting is also sparse. A recent study in SA reported a $4 \%$ prevalence of multimorbidity among adult populations, with the majority $(70 \%)$ of those who were affected being women, ${ }^{[17]}$ highlighting the potential gender dimension of this problem. Owing to the limited information on NCD multimorbidity in SA, there is little wellestablished contextual evidence to inform current policy decisions to prevent and control its rising burden. 


\section{Objectives}

In light of the above, the objective of this study was to investigate the prevalence, awareness and control of patterns of comorbid hypertension and diabetes and the underlying risk factors in KwaZulu-Natal (KZN) Province, SA. Various studies have reported evidence of the burden of hypertension and diabetes in KZN. ${ }^{[18-20]}$ Although diabetes and hypertension are the most common NCDs $(40-60 \%),{ }^{[21,22]}$ the extent of their coexistence in KZN is unknown. While findings from the present study will help bridge the knowledge gap on NCD multimorbidity in SA, and by extension in many LMICs, they may also be relevant to inform the development of health policies to ameliorate the current multimorbidity burden and strengthen the health system to provide better care for patients with such multimorbidity.

\section{Methods}

\section{Source of data}

The data for this study were gathered in KZN. The project was conducted in rural and periurban communities in the province between January and June 2015, by the SA Human Sciences Research Council (HSRC). ${ }^{[23]}$ The objective of the project was to understand the complexity, severity and prevalence of NCDs in a community with high HIV incidence and prevalence (Mpumza, home to 50 000 people). The project was a follow-up of a previous HIV home-based counselling and testing (HBCT) study conducted in November 2011 and June 2012. The HIV data were not made available. The NCD data were anonymised before they were made available online. Informed consent was provided by each participant during the data collection.

In 2011/2012, a sample of 545 Mpumza households were randomly selected. Adults aged $\geq 18$ years were invited to participate in the study. All the participants who were enrolled during the HBCT study in 2011/2012 and were present in 2015 were invited to participate in the follow-up study. Respondents for this study were all the 587 participants whose data were made available by the HSRC.

\section{Measurements}

Hypertension prevalence, awareness, treatment and control Consenting study participants had their blood pressure measured in accordance with the American Heart Association recommendations using Omron HBP-1300-E devices (Omron Global, Japan). Three blood pressure readings were taken at 10-minute resting intervals. The last two measurements were used in the study. Hypertension was defined as an average systolic blood pressure (SBP) $\geq 140 \mathrm{mmHg}$ and/or an average diastolic blood pressure (DBP) $\geq 90 \mathrm{mmHg}$, ${ }^{[24]}$ or self-report of having been diagnosed with hypertension by a medical professional. ${ }^{[24,25]}$ Among participants who were classified as hypertensive, hypertension awareness was defined as self-report of previous diagnosis by a health professional. Hypertension treatment was investigated among participants who self-reported that they were living with hypertension. Hypertension treatment was defined as use of an antihypertensive in the past 2 weeks and categorised as 1 (treatment of hypertension) or 0 (no treatment of hypertension). Hypertension control was checked among participants who were on treatment. Hypertension control was defined as an average SBP $<140$ $\mathrm{mmHg}$ and/or an average DBP $<90 \mathrm{mmHg}$.

\section{Diabetes prevalence, awareness, treatment and control}

The careET-202 EasyTouch GC device (Roche Diabetes Care South Africa (Pty) Ltd.) and test strips were used to measure random plasma glucose. A push-button lancet safety needle was used to draw blood from the finger. Participants were classified as having diabetes if their plasma blood glucose level was $\geq 11 \mathrm{mmol} / \mathrm{L}$ or they self-reported prior diagnosis of diabetes by a medical professional. ${ }^{[26]}$ Among those who had diabetes, diabetes awareness was defined as self-report of previous diagnosis by a health professional. The American Diabetes Association and the European Association for the Study of Diabetes have recommended that a combination of pharmacological treatment and lifestyle changes is essential for the management of type 2 diabetes. ${ }^{[26]}$ Diabetes treatment was defined as taking insulin or other blood sugar-lowering medication in the past 2 weeks and following a special diet, exercise regimen or weight control programme. If a respondent said yes to both the pharmacological and lifestyle diabetes treatment questions, they were classified as 1 (treatment of diabetes); those who responded no were classified as 0 (no treatment of diabetes). Participants living with diabetes with a blood glucose level $<7.8 \mathrm{mmol} / \mathrm{L}$ were considered to be controlled as determined by the International Diabetes Federation guideline. ${ }^{[27]}$

\section{Comorbidities prevalence, awareness, treatment and control}

The outcome variable for the present study was comorbid hypertension and diabetes. We were interested in the prevalence, awareness, treatment and control of these comorbid conditions. We defined comorbidities as the coexistence of hypertension and diabetes. ${ }^{[28]}$ Patients were categorised as 0 (no condition); 1 (single condition, for individuals with either hypertension or diabetes) or 2 (comorbidities, for participants with both hypertension and diabetes). Among participants living with comorbidities, awareness was defined as selfreported diagnosis of both hypertension and diabetes. Comorbidities awareness was categorised as 0 (no awareness, if the participant was unaware of living with both hypertension and diabetes) and 1 (aware, if the participant was aware of living with both diabetes and hypertension). Using diabetes and hypertension treatment, treatment of comorbidities was measured. The sample size was very small at this stage, so a variable was created based on the various forms of treatment the participants reported. These were 0 (none), 1 (lifestyle changes, insulin and antihypertensive), 2 (antihypertensive), 3 (insulin and antihypertensive), 4 (antihypertensive and lifestyle changes), and 5 (lifestyle changes and insulin). Control of comorbidities was defined as 0 (none controlled), 1 (comorbidities controlled, for participants who had both hypertension and diabetes controlled), 2 (diabetes controlled) and 3 (hypertension controlled).

\section{Independent variables}

Sociodemographic data used included age (15 - 25, 26 - 35, 36 - 45, 46 - 55 and $\geq 55$ years) and sex (male, female). In addition, marital status was defined as never married, currently married and formerly married. Religious affiliation was defined as none, Christian and traditional. Socioeconomic data included level of education (none, primary, secondary, tertiary) and wealth quintiles (poorest, poor, middle, richer and richest). Principal component analysis was used to create the wealth index. The household assets used were electricity, motor vehicle, fridge, microwave, washing machine, landline, cell phone, radio, video machine, DSTV, computer, internet and television. The wealth index was equally divided into five groups to create wealth quintiles following the Demographic and Health Survey methodology. ${ }^{[29]}$ The quintiles were poorest, poor, middle, richer and richest.

The lifestyle risk factors included in the analysis were substance use (alcohol and smoking), fruit and vegetable intake, self-rated health, and body mass index. Participants who had never consumed alcohol were classified as non-drinkers, those who had consumed alcohol but not in the past 30 days were classified as occasional 
drinkers, and participants who had consumed alcohol in the past 30 days were classified as regular drinkers. Participants were asked if they had ever smoked. Those who said yes were classified as smokers. Participants were asked to indicate the number of servings of fruits and vegetables they consumed daily. The responses were categorised into $\leq 1$ servings daily, 2 - 3 servings daily, 4 - 5 servings daily and $>5$ servings daily. Body mass index (BMI) was measured using weight $(\mathrm{kg})$ and height $(\mathrm{cm})$ information collected during the survey, and categorised as underweight $\left(<18.5 \mathrm{~kg} / \mathrm{m}^{2}\right)$, normal weight $(18.5$ $\left.24.9 \mathrm{~kg} / \mathrm{m}^{2}\right)$, overweight $\left(25-29.9 \mathrm{~kg} / \mathrm{m}^{2}\right)$ and obese $\left(\geq 30 \mathrm{~kg} / \mathrm{m}^{2}\right) .{ }^{[30]}$

\section{Statistical analyses}

Percentages were used to describe all the variables. Cross-tabulations and $\chi^{2}$ tests were used to describe the variations in prevalence of hypertension, diabetes and comorbidities according to the sociodemographic and socioeconomic variables, and lifestyle risk factors. Owing to the small numbers for some of the cells, we could not fit multivariate models for the prevalence, awareness, treatment and control of hypertension, diabetes and comorbidities. For the same reason, control of comorbidities was only examined by type of treatment.

\section{Ethical considerations}

The HSRC was granted ethical clearance for data collection by both the HSRC Ethics Committee (ref. no. 1/26/05/11) and the University of Washington Institutional Review Board (ref. no. 48733). Only individuals who consented were enrolled in the survey.

\section{Results}

\section{Background characteristics}

A total of 587 participants were enrolled. Approximately two-thirds were female (69\%) (Table 1). Ages ranged from 19 to 94 years (mean (standard deviation) 43.2 (17.2) years). Approximately a third had attained secondary school and a third high school levels of education (32\% and $33 \%$, respectively). More than half of the participants had never married (67\%), and the majority were Christians (76\%). Approximately two-thirds of the participants were in the poorest, poor and middle wealth quintile categories.

Seventeen percent of the participants were smokers, and close to half were regular drinkers (45\%). Fruit and vegetable intake was low, $<4 \%$ of the participants consuming $4-5$ servings daily ( $2 \%$ and $3 \%$, respectively). About $8 \%$ more men than women rated themselves as having very good health ( $38 \%$ v. $30 \%)$. With regard to BMI, more than two-fifths of the participants (46\%) were obese. A higher proportion of women were obese compared with men (60\% v. $16 \%)$.

\section{Distribution of the prevalence, awareness, treatment and control of hypertension according to background characteristics}

Table 2 shows the prevalence, awareness, treatment and control of hypertension according to background characteristics. Approximately a third of the sample had hypertension (32\%). The prevalence of hypertension was twice as high among women than among men $(p=0.00)$, and increased significantly with age and marital status. The prevalence of hypertension was also higher among those who rated their health as moderate (53\%), bad (67\%) and very bad $(83 \%)$ than among those who rated it as good or very good. BMI was associated with hypertension in this sample. A higher proportion of subjects who were overweight and obese had hypertension (30\% and $45 \%$, respectively) compared with those who were of normal weight (12\%).
Of respondents living with hypertension, $\sim 82 \%$ were aware of their status. Religion was the only significant variable that predicted awareness of hypertension status $(p=0.022) ; \sim 86 \%$ of participants who self-identified as Christian and traditionalist were aware of their hypertension status, compared with $63 \%$ of those with no religion.

Although $\sim 82 \%$ of the sample were aware of their hypertension status, only $73 \%$ were on treatment. Hypertension treatment was significantly associated with age, level of education and smoking status. A higher proportion of participants aged $45-54$ years $(71 \%)$ were on treatment compared with those aged 15 - 24 (33\%) $(p=0.001)$. The proportion of participants on treatment was lower among those with higher education (50\%) compared with those with no education (87\%) $(p=0.017)$. More participants who did not smoke $(76 \%)$ were on treatment compared with those who smoked (53\%) $(p=0.036)$.

Hypertension control was generally low in this sample. Approximately a third of the participants who were on treatment had their blood pressure controlled (37\%). Hypertension control was lower among those who were overweight and obese compared with those who were of normal weight $(p=0.041)$. With regard to wealth quintiles, a little above half of those in the poor $(54 \%)$ and richer group $(53 \%)$ had their blood pressure controlled $(p=0.029)$.

\section{Distribution of the prevalence, awareness, treatment and control of diabetes according to background characteristics}

The prevalence of diabetes in this sample was 9\% (Table 3). Diabetes prevalence was significantly associated with sex, age, level of education, marital status, smoking status, self-rated health and BMI. Diabetes prevalence was higher among females compared with males, and increased with age. Approximately two out of five participants aged $\geq 55$ years had diabetes (20\%) compared with those aged 15 24 years $(3 \%)(p=0.000)$. A third of participants who had formerly been married had diabetes (32\%) compared with $5 \%$ of the nevermarried $(p=0.000)$. The prevalence of diabetes was higher among those who reported that their health was bad (23\%) compared with those who said it was very good $(3 \%)(p=0.000)$. Approximately $14 \%$ of those were obese were living with diabetes $(p=0.000)$.

Approximately four out of five people living with diabetes were aware of their status (79\%). The variables that significantly predicted diabetes awareness were age $(p=0.000)$ and marital status $(p=0.000)$. Individuals in the older age categories tended to be more aware of their status compared with those in the younger age groups. For example, the majority of participants aged 45 - 54 years (80\%) and $\geq 55$ years (91\%) were aware of their status, while for those aged 25 34 years the figure was $50 \%$.

All the men were on treatment, while $\sim 16 \%$ of women were not on treatment. Although not significant, the proportion on treatment was higher among respondents aged $\geq 55$ (93\%) and 45 - 54 years $(75 \%)$ compared with those aged 25 - 34 years (50\%). Among participants living with diabetes, all of those with higher education (100\%) were on treatment compared with only two-thirds $(67 \%)$ of those with primary education $(p=0.003)$. All participants who were formerly married were on treatment $(100 \%)$ compared with two-thirds of those who had never married (62\%) $(p=0.005)$. Only one out of five participants had their glucose controlled (23\%). Diabetes control was not significantly related to any of the predicting variables.

Distribution of the prevalence, awareness and treatment of comorbidities according to background characteristics Table 4 illustrates the prevalence of comorbid hypertension and diabetes according to sociodemographic, socioeconomic and lifestyle 


\begin{tabular}{|c|c|c|c|}
\hline Variable & Male $(n=183), \%$ & Female $(n=404), \%$ & Total $(N=587), \%$ \\
\hline \multicolumn{4}{|l|}{ Age (years) } \\
\hline $15-24$ & 16.9 & 9.4 & 11.7 \\
\hline $25-34$ & 28.4 & 27.0 & 27.4 \\
\hline $35-44$ & 18.0 & 21.0 & 20.1 \\
\hline $45-54$ & 14.2 & 12.4 & 12.9 \\
\hline$\geq 55$ & 22.4 & 30.2 & 27.8 \\
\hline \multicolumn{4}{|l|}{ Level of education } \\
\hline No education & 10.4 & 15.1 & 13.6 \\
\hline Primary & 19.7 & 18.1 & 18.6 \\
\hline Secondary school & 32.2 & 32.2 & 32.2 \\
\hline High school & 34.4 & 32.9 & 33.4 \\
\hline Tertiary & 3.3 & 1.7 & 2.2 \\
\hline \multicolumn{4}{|l|}{ Marital status } \\
\hline Never married & 68.3 & 66.3 & 67.0 \\
\hline Currently married & 28.4 & 23.5 & 25.0 \\
\hline Formerly married & 3.3 & 10.1 & 8.0 \\
\hline \multicolumn{4}{|l|}{ Religion } \\
\hline None & 37.2 & 11.6 & 19.6 \\
\hline Christian & 58.5 & 84.2 & 76.2 \\
\hline Traditional & 4.4 & 4.2 & 4.3 \\
\hline \multicolumn{4}{|l|}{ Wealth quintiles } \\
\hline Poorest & 23.5 & 19.5 & 20.8 \\
\hline Poor & 22.9 & 22.8 & 22.8 \\
\hline Middle & 17.5 & 26.7 & 23.8 \\
\hline Richer & 18.0 & 13.4 & 14.8 \\
\hline Richest & 18.0 & 17.6 & 17.7 \\
\hline \multicolumn{4}{|l|}{ Smoking status } \\
\hline Smoker & 40.4 & 6.0 & 17.0 \\
\hline Non-smoker & 59.6 & 94.0 & 83.0 \\
\hline \multicolumn{4}{|l|}{ Alcohol use } \\
\hline None & 46.4 & 49.7 & 48.7 \\
\hline Occasional & 14.7 & 2.7 & 6.5 \\
\hline Regular & 38.8 & 47.5 & 44.8 \\
\hline \multicolumn{4}{|c|}{ Fruit intake (servings/day) } \\
\hline$\leq 1$ & 65.6 & 55.2 & 58.4 \\
\hline $2-3$ & 32.2 & 42.1 & 39.0 \\
\hline $4-5$ & 1.6 & 2.2 & 2.0 \\
\hline$>5$ & 0.6 & 0.5 & 0.6 \\
\hline \multicolumn{4}{|c|}{ Vegetable intake (servings/day) } \\
\hline$\leq 1$ & 34.3 & 31.9 & 32.7 \\
\hline $2-3$ & 62.3 & 64.6 & 63.9 \\
\hline $4-5$ & 3.4 & 3.5 & 3.4 \\
\hline \multicolumn{4}{|l|}{ Self-rated health } \\
\hline Very good & 37.7 & 30.2 & 32.5 \\
\hline Good & 38.2 & 33.4 & 34.9 \\
\hline Moderate & 19.1 & 29.7 & 26.4 \\
\hline Bad & 4.9 & 5.2 & 5.1 \\
\hline Very bad & 0 & 1.5 & 1.0 \\
\hline \multicolumn{4}{|l|}{ BMI } \\
\hline Underweight & 3.8 & 1.5 & 2.2 \\
\hline Normal weight & 51.9 & 14.6 & 26.2 \\
\hline Overweight & 28.4 & 23.8 & 25.2 \\
\hline Obese & 15.8 & 60.1 & 46.3 \\
\hline Total & 100 & 100 & 100 \\
\hline
\end{tabular}


Table 2. Prevalence, awareness, treatment and control of hypertension according to background characteristics

\begin{tabular}{|c|c|c|c|c|}
\hline Variable & Prevalence $(N=587), \%$ & Awareness $(n=188), \%$ & Treatment $(n=154), \%$ & Control $(n=112), \%$ \\
\hline \multicolumn{5}{|l|}{ Sex } \\
\hline Male & $19.1^{*}$ & 71.4 & 80.0 & 30.0 \\
\hline Female & 37.9 & 84.3 & 71.3 & 38.0 \\
\hline \multicolumn{5}{|l|}{ Age (years) } \\
\hline $15-24$ & $4.3^{*}$ & 100 & 33.3 & 0 \\
\hline $25-34$ & 9.9 & 75.0 & 33.3 & 20.0 \\
\hline $35-44$ & 22.0 & 76.9 & 55.0 & 60.0 \\
\hline $45-54$ & 36.8 & 75.0 & 71.4 & 33.3 \\
\hline$\geq 55$ & 70.6 & 85.2 & 82.7 & 35.8 \\
\hline \multicolumn{5}{|l|}{ Level of education } \\
\hline No education & $56.2^{*}$ & 84.4 & 86.8 & 48.5 \\
\hline Primary & 48.6 & 88.7 & 80.8 & 34.2 \\
\hline Secondary school & 30.7 & 77.6 & 62.2 & 28.6 \\
\hline High school & 14.8 & 75.9 & 54.5 & 33.3 \\
\hline Tertiary & 23.1 & 66.7 & 50.0 & 0 \\
\hline \multicolumn{5}{|l|}{ Marital status } \\
\hline Never married & 21.4 & 80.9 & 63.2 & 40.5 \\
\hline Currently married & 49.7 & 80.8 & 81.4 & 34.7 \\
\hline Formerly married & 66.0 & 87.1 & 77.8 & 33.3 \\
\hline \multicolumn{5}{|l|}{ Religion } \\
\hline None & 23.5 & $63.0^{*}$ & 76.5 & 69.2 \\
\hline Christian & 28.0 & 85.7 & 83.3 & 40.0 \\
\hline Traditional & 34.5 & 85.1 & 71.8 & 31.9 \\
\hline \multicolumn{5}{|l|}{ Wealth index } \\
\hline Poorest & 37.7 & 84.8 & 71.8 & $35.7^{*}$ \\
\hline Poor & 32.1 & 83.7 & 72.2 & 53.8 \\
\hline Middle & 27.9 & 84.6 & 78.8 & 16.0 \\
\hline Richer & 31.0 & 77.8 & 76.2 & 52.9 \\
\hline Richest & 31.7 & 75.8 & 64.0 & 25.0 \\
\hline \multicolumn{5}{|l|}{ Smoking status } \\
\hline Smoker & 22.0 & 86.4 & 52.6 & 30.0 \\
\hline Non-smoker & 34.1 & 79.2 & 75.6 & 37.2 \\
\hline \multicolumn{5}{|l|}{ Alcohol use } \\
\hline None & 32.9 & 84.0 & 77.2 & 38.3 \\
\hline Occasional & 28.9 & 72.7 & 62.5 & 20.0 \\
\hline Regular & 31.6 & 80.7 & 68.7 & 36.2 \\
\hline \multicolumn{5}{|c|}{ Fruit intake (servings/day) } \\
\hline$\leq 1$ & 32.1 & 80.9 & 79.8 & 38.0 \\
\hline $2-3$ & 32.3 & 82.4 & 62.3 & 31.6 \\
\hline $4-5$ & 25.0 & 100 & 66.7 & 50.0 \\
\hline$>5$ & 33.3 & 100 & 100 & 100 \\
\hline \multicolumn{5}{|c|}{ Vegetable intake (servings/day) } \\
\hline$\leq 1$ & 26.6 & 86.3 & 79.5 & 37.1 \\
\hline $2-3$ & 34.3 & 80.9 & 71.7 & 36.8 \\
\hline $4-5$ & 30.0 & 66.7 & 25 & 0 \\
\hline \multicolumn{5}{|l|}{ Self-rated health } \\
\hline Very good & 16.2 & 80.6 & 72 & 38.9 \\
\hline Good & 24.4 & 74.0 & 64.7 & 20.8 \\
\hline Moderate & 52.9 & 84.2 & 79.7 & 40.0 \\
\hline $\mathrm{Bad}$ & 66.7 & 90.0 & 66.7 & 50.0 \\
\hline Very bad & 83.3 & 100 & 60 & 33.3 \\
\hline \multicolumn{5}{|l|}{ BMI } \\
\hline Underweight & 15.4 & 100 & 100 & $100^{*}$ \\
\hline Normal weight & 12.3 & 68.4 & 61.5 & 0.0 \\
\hline Overweight & 30.4 & 84.4 & 63.2 & 40.0 \\
\hline Obese & 44.9 & 82.8 & 77.2 & 37.7 \\
\hline Total & 32.03 & 81.9 & 72.7 & 36.6 \\
\hline
\end{tabular}




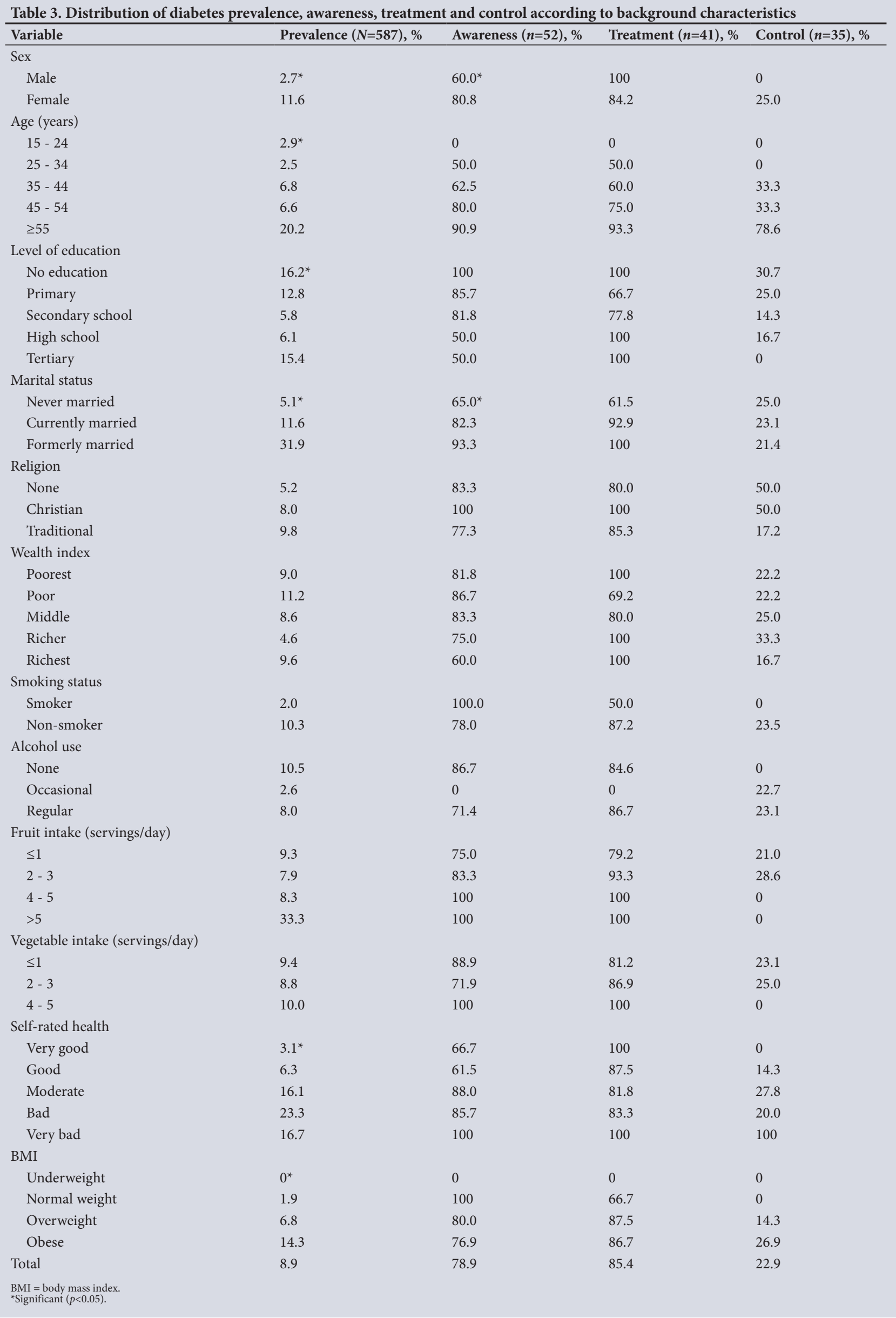




\section{Table 4. Distribution of comorbidities prevalence}

\begin{tabular}{|c|c|c|c|}
\hline Variable & None, $\%$ & Single condition, $\%$ & Comorbidities, \% \\
\hline \multicolumn{4}{|l|}{ Sex } \\
\hline Male & $79.8^{*}$ & 18.6 & 1.6 \\
\hline Female & 58.7 & 33.2 & 8.2 \\
\hline \multicolumn{4}{|l|}{ Age (years) } \\
\hline $15-24$ & $92.7^{*}$ & 7.2 & 0 \\
\hline $25-34$ & 87.6 & 12.4 & 0 \\
\hline $35-44$ & 73.7 & 23.7 & 2.5 \\
\hline $45-54$ & 60.5 & 35.5 & 3.9 \\
\hline$\geq 55$ & 27.6 & 54.0 & 18.4 \\
\hline \multicolumn{4}{|l|}{ Level of education } \\
\hline No education & 41.2 & 45.0 & 13.7 \\
\hline Primary & 49.5 & 39.4 & 11.0 \\
\hline Secondary school & 68.2 & 27.0 & 4.8 \\
\hline High school & 80.6 & 17.9 & 1.5 \\
\hline Tertiary & 69.2 & 23.1 & 7.7 \\
\hline \multicolumn{4}{|l|}{ Marital status } \\
\hline Never married & $75.8^{*}$ & 21.9 & 2.3 \\
\hline Currently married & 48.3 & 42.2 & 9.5 \\
\hline Formerly married & 29.8 & 42.6 & 27.7 \\
\hline \multicolumn{4}{|l|}{ Religion } \\
\hline None & 74.8 & 21.7 & 3.5 \\
\hline Christian & 72.0 & 20.0 & 8.0 \\
\hline Traditional & 62.4 & 30.9 & 6.7 \\
\hline \multicolumn{4}{|l|}{ Wealth index } \\
\hline Poorest & 61.5 & 30.3 & 8.2 \\
\hline Poor & 64.2 & 28.4 & 7.5 \\
\hline Middle & 67.9 & 27.9 & 4.3 \\
\hline Richer & 67.0 & 26.4 & 4.6 \\
\hline Richest & 64.2 & 29.8 & 5.8 \\
\hline \multicolumn{4}{|l|}{ Smoking status } \\
\hline Smoker & 77.0 & 22.0 & 1.0 \\
\hline Non-smoker & 62.8 & 23.0 & 7.2 \\
\hline \multicolumn{4}{|l|}{ Alcohol use } \\
\hline None & 64.3 & 28.0 & 7.7 \\
\hline Occasional & 71.0 & 26.3 & 2.6 \\
\hline Regular & 65.4 & 29.7 & 4.9 \\
\hline \multicolumn{4}{|c|}{ Fruit intake (servings/day) } \\
\hline$\leq 1$ & 64.1 & 30.3 & 5.5 \\
\hline $2-3$ & 66.4 & 27.1 & 6.6 \\
\hline $4-5$ & 75.0 & 16.7 & 8.3 \\
\hline$>5$ & 66.7 & 0 & 33.3 \\
\hline \multicolumn{4}{|c|}{ Vegetable intake (servings/day) } \\
\hline$\leq 1$ & 68.7 & 26.6 & 4.7 \\
\hline $2-3$ & 63.2 & 30.1 & 6.7 \\
\hline $4-5$ & 70.0 & 30.0 & 10.0 \\
\hline \multicolumn{4}{|l|}{ Self-rated health } \\
\hline Very good & 82.2 & 16.2 & 1.6 \\
\hline Good & 73.2 & 22.9 & 3.9 \\
\hline Moderate & 42.6 & 45.8 & 11.6 \\
\hline $\mathrm{Bad}$ & 33.3 & 43.3 & 23.3 \\
\hline Very bad & 0 & 100 & 0 \\
\hline \multicolumn{4}{|l|}{ BMI } \\
\hline Underweight & 84.6 & 15.4 & 0 \\
\hline Normal weight & 87.0 & 11.7 & 1.3 \\
\hline Overweight & 68.2 & 26.3 & 5.4 \\
\hline Obese & 50.4 & 40.1 & 9.5 \\
\hline Total & 65.2 & 28.6 & 6.1 \\
\hline
\end{tabular}


factors. The overall prevalence of comorbidities was 6\%. A higher proportion of women $(8 \%)$ had comorbidities compared with men $(2 \%)$ $(p=0.000)$. The prevalence of comorbidities increased with age. The age group $>55$ years had a significantly higher proportion of participants living with comorbidities (18\%) than the younger age groups, and none of those aged 15 - 34 years had comorbid hypertension and diabetes. In addition, the prevalence of comorbidities among participants who had no education was $\sim 14 \%$, while those with tertiary education had a prevalence of $\sim 8 \%$. A significant association between marital status and comorbidities was also found. The prevalence of comorbidities was highest among those who had formerly been married (28\%) and lowest among those who had never married (2\%). Although the association was not significant, the prevalence of comorbidities was higher in poor households compared with richer households.

One of five participants who rated their health as bad had comorbidities (23\%). As expected, a significant association was found between BMI and comorbidities. Participants who were obese recorded the highest prevalence of comorbidities (10\%), compared with $1 \%$ of those of normal weight. Fruit and vegetable intake and alcohol use were not significantly associated with comorbidities.

Table 5 presents levels of awareness of comorbidities and the treatments the participants were using. The majority of the respondents (86\%) were aware of their conditions. Most were on treatment, and many (74\%) followed the recommended combination of lifestyle changes, insulin and antihypertensive medication. However, some of the participants did not follow the recommended treatment. Approximately $7 \%$ were only on pharmacological treatment with no lifestyle changes. Another 3\% only treated their hypertension and diabetes, respectively.

Control of comorbidities is shown in Table 6. A high proportion of the participants had uncontrolled hypertension and diabetes

\begin{tabular}{ll}
\multicolumn{2}{l}{ Table 5. Awareness and treatment of comorbidities } \\
\hline Awareness and treatment & $\boldsymbol{n}(\%)$ \\
\hline Awareness & \\
Aware & $31(86.1)$ \\
Unaware & $5(13.9)$ \\
Total & $36(100)$ \\
Treatment & \\
No treatment & $3(9.7)$ \\
Lifestyle changes, insulin, antihypertensive & $23(74.2)$ \\
Antihypertensive & $1(3.2)$ \\
Insulin and antihypertensive & $2(6.5)$ \\
Antihypertensive and lifestyle changes & $1(3.2)$ \\
Lifestyle changes and insulin & $1(3.2)$ \\
Total & $31(100)$ \\
&
\end{tabular}

(71\%). Approximately $17 \%$ of the participants who had controlled comorbidities were those who were using the lifestyle change, insulin and antihypertensive treatment regimen. All the participants who were not on treatment were uncontrolled.

\section{Discussion \\ Hypertension prevalence, awareness, treatment and control}

The study revealed that a third of the respondents in rural KZN were living with hypertension; $73 \%$ were on treatment, while more than a third of those treated were controlled. The prevalence was relatively low in this study compared with two studies on hypertension in SA and one comparative study in SA and Ghana. In a study of comorbidities in the Agincourt study site in SA, a prevalence of $63 \%$ was found. ${ }^{[31]}$ In Wave 2 of the World Health Organization-funded Global Study on Ageing and Adult Health (SAGE), a hypertension prevalence of $43 \%$ was reported. ${ }^{[32]}$ Furthermore, while we found a $37 \%$ control rate, more recent hypertension studies in SA report much lower levels of control $(18-24 \%) .^{[31,32]}$ The same pattern was observed for awareness and treatment. We found higher levels of awareness and treatment of hypertension compared with other studies. These differences could be explained by differences in the study population and perhaps the methodology. The SAGE data are primarily focused on the elderly population and therefore more likely to have higher estimates for conditions that are sensitive to ageing. Hypertension control is lower among the elderly for a variety of reasons, including limited income and having to depend on others for help. These reasons may challenge the drive for optimal hypertension treatment and subsequent control. However, our findings were consistent with regional-level hypertension studies where broad levels of prevalence were noted among different subpopulations. ${ }^{[33-35]}$ Crucially, over the past few years, hypertension and related complications have become a major part of the epidemiological profile both in SA and the broader African region.

\section{Diabetes prevalence, awareness, treatment and control}

The study showed that $9 \%$ of the respondents in rural KZN had type 2 diabetes, and this is slightly lower than the national estimate of $9.8 \%{ }^{[36]}$ Among individuals with diabetes, $79 \%$ were aware that they had it, and $>85 \%$ of those who were aware of their condition were receiving treatment for it. Slightly more than one-fifth of those receiving treatment achieved adequate glycaemic control through treatment; this proportion is slightly higher than that observed in a study conducted in rural KZN (15.7\%) describing the nature of care, glycaemic control and diabetes complications among patients with diabetes receiving treatment from a public hospital. ${ }^{[37]}$

The results clearly show that glycaemic control is a challenge in this population. Evidence from the KZN Department of Health showed

Table 6. Control of comorbidities according to type of treatment

\begin{tabular}{lllll} 
Table 6. Control of comorbidities according to type of treatment \\
\cline { 2 - 5 } Treatment & \multicolumn{4}{c}{ Control, \% } \\
\hline No treatment & 100 & - & - & - \\
Lifestyle changes, insulin, antihypertensive & 69.6 & 17.4 & - & 13.0 \\
Antihypertensive & - & - & - & 100 \\
Insulin and antihypertensive & 100 & - & - & - \\
Antihypertensive and lifestyle changes & 100 & - & 100 & - \\
Lifestyle changes and insulin & - & - & 3.2 & - \\
Total & 70.9 & 12.9 & & 12.9
\end{tabular}


that the number of clinic visits by diabetic patients in the province has increased significantly over time. ${ }^{[38]}$ Coupled with this, the large majority of people diagnosed with diabetes are seeking medical care, and the number of treatment defaulters reduced significantly between 2006 and 2016. ${ }^{[38]}$ What is unclear is why, despite these impressive success stories, glycaemic control remains a problem in the study area. Research revealed that adequate glycaemic control can reduce the risk of cardiovascular diseases in patients with diabetes. ${ }^{[39]}$ Nevertheless, the relatively low glycaemic control in this population suggests the need for urgent interventions to minimise diabetes complications such as microvascular (neuropathy, nephropathy and retinopathy) and macrovascular (stroke and peripheral vascular disease) disorders. ${ }^{[40]}$ Such interventions may be achieved by strengthening the local clinics in the province in terms of resources, staffing and clinician education. ${ }^{[41]}$

Furthermore, the findings showed that sociodemographic characteristics such as sex, age, marital status and level of education play important roles in diabetes prevalence and awareness, just as has been found in previous studies. ${ }^{[22,43]}$ It will be important to leverage existing interventions on these sociodemographic characteristics in developing a policy action plan to reduce the burden of diabetes in KZN.

\section{Comorbidities of diabetes and hypertension}

To the best of our knowledge, this is the first community-based study in SA to present information about comorbid hypertension and diabetes prevalence, awareness, treatment and control in a rural population. The study showed that the prevalence of comorbid hypertension and diabetes was $6 \%$, and the figure was significantly higher among women, individuals aged $\geq 55$ years, and those who were formerly married. The co-occurrence of diabetes and hypertension observed in this study is higher than that reported in similar populations in Nepal $(1.8 \%)^{[44]}$ and India (4.1\%). ${ }^{[4]}$ Although this prevalence seems low, it deserves critical attention, as research has shown that comorbid diabetes and hypertension increase the risk of developing macrovascular and microvascular diseases. ${ }^{[46-48]}$

The findings showed that the majority of respondents with comorbid hypertension and diabetes were aware of their conditions and were treating them using lifestyle changes, insulin and antihypertensive medications. However, only about one-tenth achieved hypertension and glycaemic control. The issue of comorbid control is clearly a problem in this population, despite a high level of treatment. Plausible explanations for the low level of comorbid hypertension and diabetes control in this population are that the medications used by the respondents were ineffective, or that there are non-adherence issues. There are three research implications for this. First, in future studies it will be important to explore factors accounting for poor hypertension and glycaemic control in KZN despite treatment. Second, future studies need to explore the level of medication adherence among those living with comorbidities of hypertension and diabetes. Third, it will be of great benefit to study the potency of antihypertensive and diabetes medications used in this population.

\section{Study limitations}

This study is not without limitations. The data were collected in 2015, and the findings may not reflect current hypertension, diabetes and comorbidities experiences in KZN. However, although this dataset was gathered in 2015, it is the first time such an analysis has been conducted using this dataset. More importantly, this study can be used as a baseline to evaluate the effectiveness of recent interventions by the government to address obesity and NCDs in SA. Furthermore, the sample size for this study was too small to do rigorous analysis. As a result, multivariate analysis could not be carried out to examine the determinants of awareness, treatment and control of hypertension and diabetes comorbidities in this population. Nevertheless, the findings provide an important description and representation of the burden of hypertension and diabetes comorbidities in KZN.

\section{Conclusions}

This study examined the prevalence, awareness, treatment and control of comorbid hypertension and diabetes and the underlying risk factors in Mpumza, KZN, SA. The prevalence of comorbidities was $6 \%$. Although this prevalence seems low, it was higher among vulnerable populations, particularly women, the obese, the poor and those with a low level of education. Furthermore, control of comorbidities was also low despite a high proportion of participants being on treatment. It is important to pay critical attention to this problem, as poor control has the potential to increase the risk of macrovascular and microvascular diseases and reduce gains towards achieving health and wellbeing, as specified by the SDGs.

Declaration. None.

Acknowledgements. The authors are grateful to the HRSC for giving them access to the non-communicable disease screening and HIV testing and counselling in rural KZN 2015 project data. The data are available on the HSRC website (http://curation.hsrc.ac.za/index.php?module=pagesetter \&type $=$ user\&func $=$ hsrcdataset $\&$ ppnumber=SPAIAA\&datasetno $=1$ ).

Author contributions. SBK and OAS conceptualised the study. SBK conducted the data analysis. LB drafted the introduction section. SBK, EKA and RBA drafted the methods section. OAS and MKK drafted the discussion section. All authors contributed to the first draft. The final draft was reviewed, edited and approved by all authors. SBK was awarded the funds for the publication fees.

Funding. The publication fee was supported by a Researcher Links travel grant, ID RLTG10, under the Newton Fund Grant partnership. The grant is funded by the UK Department for Business, Energy and Industrial Strategy and Department of Higher Education and Training and delivered by the British Council. For further information, please visit www. newtonfund.ac.uk

Conflicts of interest. None.

1. Nishtar S, Niinistö S, Sirisena M, et al. Time to deliver: Report of the WHO Independent HighLevel Commission on NCDs. Lancet 2018;392(10143):245-252. https://doi.org/10.1016/S0140 6736(18)31258-3

2. Ordunez P, Campbell NRC. Beyond the opportunities of SDG 3: The risk for the NCDs agenda. Lancet Diabetes Endocrinol 2016;4(1):15-17. https://doi.org/10.1016/s2213-8587(15)00488-x

Naghavi M, Forouzanfar MH. Burden of non-communicable diseases in sub-Saharan Africa in 1990 and 2010: Global Burden of Diseases, Injuries, and Risk Factors Study 2010. Lancet 2013;381:S95. and 2010: Global Burden of Diseases, Injuries,
https://doi.org/10.1016/S0140-6736(13)61349-5

4. Lozano R, Naghavi M, Foreman K, et al. Global and regional mortality from 235 causes of death for 20 age groups in 1990 and 2010: A systematic analysis for the Global Burden of Disease Study 2010. 20 age groups in 1990 and 2010: A systematic analysis for the Global Burden of Disease
Lancet 2012;380(9859):2095-2128. https://doi.org/10.1016/s0140-6736(12)61728-0

5. Lefèvre T, d'Ivernois J-F, de Andrade V, Crozet C, Lombrail P, Gagnayre R. What do we mean by multimorbidity? An analysis of the literature on multimorbidity measures, associated factors, and impact on health services organization. Rev Epidemiol Sante Publique 2014;62(5):305-314. https:// doi.org/10.1016/j.respe.2014.09.002

6. Hajat C, Stein E. The global burden of multiple chronic conditions: A narrative review. Prev Med Rep 2018;19(12):284-293. https://doi.org/10.1016/j.pmedr.2018.10.008

Garin N, Koyanagi A, Chatterii S, et al. Global multimorbidity patterns: A cross-sectional, populationbased, multi-country study. J Gerontol Ser A 2016;71(2):205-214. https://doi.org/10.1093/gerona/ glv128

8. Whitney DG, Hurvitz EA, Ryan JM, et al. Noncommunicable disease and multimorbidity in young adults with cerebral palsy. Clin Epidemiol 2018;10:511-519. https://doi.org/10.2147/clep.s159405

9. Pati S, Agrawal S, Swain S, et al. Non communicable disease multimorbidity and associated Pati S, Agrawal S, Swain S, et al. Non communicable disease multimorbidity and associated
health care utilisation and expenditures in India: Cross-sectional study. BMC Health Serv Res health care utilisation and expenditures in India: Cross-sec
2014;14(1):451. https://doi.org/10.1186/1472-6963-14-451 
10. Sum G, Hone T, Atun R, et al. Multimorbidity and out-of-pocket expenditure on medicines: A systematic review. BMJ Glob Health 2018:3(1). https://doi.org/10.1136/bmigh-2017-000505

11. Zulman DM, Chee CP, Wagner TH, et al. Multimorbidity and healthcare utilisation among high-cost patients in the US Veterans Affairs Health Care System. BMJ Open 2015;5(4). https://doi.org/10.1136/ bmjopen-2015-007771

12. Lee JT, Hamid F, Pati S, Atun R, Millett C. Impact of noncommunicable disease multimorbidity on healthcare utilisation and out-of-pocket expenditures in middle-income countries: Cross sectional analysis. PLoS ONE 2015;10(7):e0127199. https://doi.org/10.1371/journal.pone.0127199

13. Parekh AK, Barton MB. The challenge of multiple comorbidity for the US health care system. JAMA 2010;303(13):1303-1304. https://doi.org/10.1001/jama.2010.38

14. Xu X, Mishra GD, Jones M. Mapping the global research landscape and knowledge gaps on multimorbidity: A bibliometric study. J Glob Health 2017;7(1):010414. https://doi.org/10.7189/ jogh.07.010414

15. Lalkhen H, Mash R. Multimorbidity in non-communicable diseases in South African primary healthcare. S Afr Med J 2015;105(2):134-138. https://doi.org/10.7196/SAMJ.8696

16. Folb N, Timmerman V, Levitt NS, et al. Multimorbidity, control and treatment of noncommunicable diseases among primary healthcare attenders in the Western Cape, South Africa. S Afr Med 2015:105(8):642-647. https://doi.org/10.7196/SAMInew.8794

17. Alaba O, Chola L. The social determinants of multimorbidity in South Africa. Int J Equity Health 2013;12(1):63. https://doi.org/10.1186/1475-9276-12-63

18. Olowe OA, Ross AJ. Knowledge, adherence and control among patients with hypertension attending a peri-urban primary health care clinic, KwaZulu-Natal. Afr J Prim Health Care Fam Med 2017;9(1):1-5. https://doi.org/10.4102/phcfm.v9i1.1456

19. Duncan P, Howe L, Manakusa Z, Purdy S. Determinants of blood pressure control in rural KwaZuluNatal South Africa S Afr Fam Pract 2014:56(6):297-304. https.//doi org/10.1080/20786190.2014.97548

20. Adebolu FA, Naidoo M. Blood pressure control amongst patients living with hypertension presenting to an urban district hospital outpatient clinic in Kwazulu-Natal. African J Prim Health Care Fam Med 2014:6(1):1-6. https:///doi.org/10.4102/phcfm.v6i1.572

21. Kirchberger I, Meisinger C, Heier M, et al. Patterns of multimorbidity in the aged population Results from the KORA-Age study. PLoS ONE 2012;7(1):e30556. https://doi.org/10.1371/journal pone. 0030556

22. Arauz-Pacheco C, Parrott MA, Raskin P. The treatment of hypertension in adult patients with diabetes Diabetes Care 2002;25(1):134-147. https://doi.org/10.2337/diacare.25.1.134

23. Van Heerden A, Barnabas RV, Norris SA, Micklesfield LK, van Rooyen H, Celum C. High prevalence of HIV and non-communicable disease (NCD) risk factors in rural KwaZulu-Natal, South Africa. J In AIDS Soc 2017;20(2):e25012. https://doi.org/10.1002/jia2.25012

24. Sanuade OA, Boatemaa S, Kushitor MK. Hypertension prevalence, awareness, treatment and contro in Ghanaian population: Evidence from the Ghana demographic and health survey. PLoS ONE 2018;13(11):e0205985. https://doi.org/10.1371/journal.pone.020598

25. Sanuade OA, Awuah RB, Kushitor M. Hypertension awareness, treatment and control in Ghana: A crosssectional study. Ethn Health 2020;25(5)702-716. https://doi.org/10.1080/13557858.2018.1439898

26. Inzucchi SE, Bergenstal RM, Buse JB, et al. Management of hyperglycemia in type 2 diabetes, 2015 A patient-centered approach: Update to a position statement of the American Diabetes Association and the European Association for the Study of Diabetes. Diabetes Care 2015;38(1):140-149. https:/ doi.org/10.2337/dc14-2441

27. Ceriello A, Colagiuri S. International Diabetes Federation guideline for management of postmea glucose: A review of recommendations. Diabet Med 2008;25(10):1151-1156. https://doi.org/10.1111/ j.1464-5491.2008.02565.x

28. Academy of Medical Sciences. Multimorbidity: A priority for global health research. April 2018. https://acmedsci.ac uk/file-download/82222577 (accessed 10 July 2020).

29. Ghana Statistical Service. Ghana Demographic and Health Survey, 2008. Accra: GSS, GHS, and ICF Macro, 2009. https://www.dhsprogram.com/pubs/pdf/FR221/FR221\%5B13Aug2012\%5D.pd (accessed 7 July 2020).

30. World Health Organization. Global status report on noncommunicable diseases. Geneva; 2010. https:// www.who.int/nmh/publications/ncd_report2010/en/ (accessed 7 July 2020).
31. Chang AY, Gómez-Olivé FX, Manne-Goehler J, et al. Multimorbidity and care for hypertension, diabetes and HIV among older adults in rural South Africa. Bull World Health Organ 2019;97(1):10. https://doi, org/10.2471/BLT.18.217000

32. Ware LJ, Chidumwa G, Charlton K, Schutte AE, Kowal P. Predictors of hypertension awareness, treatment and control in South Africa: Results from the WHO-SAGE population survey (Wave 2). J Hum Hypertens 2019;33(2):157-166. https:// doi.org/10.1038/541371-018-0125-3

33. Kayima J, Wanyenze RK, Katamba A, Leontsini E, Nuwuha F. Hypertension awareness, treatement and control in Africa: A systematic review. BMC Cardiovasc Disord 2013;13:54. https://doi.org/10.1186/14712261-13-54

34. Addo J, Smeeth L, Leon DA. Hypertension in sub-Saharan Africa: A systematic review. Hypertension 2007;50:1012-1018. https://doi.org/10.1161/hypertensionaha.107.093336

35. Bosu WK, Reilly ST, Aheto JMK, Zucchelli E. Hypertension in older adults in Africa: A systematic review and meta-analysis. PLoS ONE 2019;14(4):e0214934. https://doi.org/10.1371/journal.pone.0214934

36. World Health Organization. Global report on diabetes. 2016. https://www.google.com/url?sa=t\&rct=i\&q $=\&$ esrc $=$ s\&source $=$ web\&cd $=\&$ ved $=2$ ahUKEwiGzaa5rIfuAhVcQ0EAHT4wD0QQFjAKegQIHBAC\&ur l=https $\% 3 \mathrm{~A} \% 2 \mathrm{~F} \% 2$ Fapps.who int\%2Firis\% 2 Frest\% 2 Fbitstreams\%2F909883\%2Fretrieve\&usg=AOvVaw 02AXavZxubgvureAliwkxG (accessed 7 July 2017).

37. Rotchford A, Rotchford K. Diabetes in rural South Africa - an assessment of care and complications. S Afr Med J 2002;92(7):536-541.

38. Sahadew N, Singaram VS. Progress in diabetes care in the KwaZulu-Natal public health sector: A decade of analysis. J Endocrinol Metab Diabetes S Afr 2019;24(3):83-91. https://doi.org/10.1080/16089677.20 19.1629080

39. Tancredi M, Rosengren A, Svensson A, et al. Glycaemic control and excess risk of major coronary events in patients with type 2 diabetes: A population-based study. Open Heart 2019;6:e000967. https://doi. rg/10.1136/openhrt-2018-00096

40. Chawla A, Chawla R, Jaggi S. Microvasular and macrovascular complications in diabetes mellitus: Distinct or continuum? Indian J Endocrinol Metab 2016;20(4):546-551. https://doi.org/10.4103/22308210.183480

41. Pillay S, Lutge E, Aldous C. The burden of diabetes mellitus in KwaZulu-Natal's public sector : A 5-year perspective. S Afr Med J 2016;106(4):384-388. https://doi.org/10.7196/SAMJ.2016.v106i4.9920

42. Miao L, Xianyu L, L Y, Jiaqi L, Yao H. Prevalence and control status of diabetes and related risk factors among 4196 Chinese male older elderly aged 80 years. Int J Gerontol 2018;12(2):122-126. https://doi. org/10.1016/j.ijge.2017.08.005

43. Liu X, Li Y, Li L, Zhang L, Ren Y, Zhou H. Prevalence, awareness, treatment, control of type 2 diabetes mellitus and risk factors in Chinese rural population: The RuralDiab study. Sci Rep 2016;6:31426. https:// doi.org/10.1038/srep31426

44. Pandey A, Karki K, Mehata S, et al. Prevalence and determinants of comorbid diabetes and hypertension in Nepal: Evidence from Non Communicable Disease Risk Factors STEPS Survey Nepal 2013. J Nepal Health Res Counc 2015;13(29):20-25.

45. Tripathy J, Thakur J, Jeet G, Jain S. Prevalence and determinants of comorbid diabetes and hypertension: Evidence from non communicable disease risk factor STEPS survey, India. Diabetes Metab Syndr 2017;11(1):S459-S465. https://doi.org/10.1016/j.dsx.2017.03.036

46. Konzem S, Devore V, Bauer D. Controlling hypertension in patients with diabetes. Am Fam Physician 2002;66(7):1209-1214

47. Fowler MJ. Microvascular and macrovascular complications of diabetes. Clin Diabetes 2008;26(2):77-82. https://doi.org/10.2337/diaclin.26.2.77

48. Mutyambizi C, Chola L, Groot W, Pavlova M, Labadarios D, Hongoro C. The extent and determinants of diabetes and cardiovascular disease comorbidity in South Africa - results from the South African National Health and Nutrition Examination Survey (SANHANES-1). BMC Public Health 2017;17:745. https://doi.org/10.1186/s12889-017-4792-8

Accepted 27 August 2020. 